Vol. 12 (1): 119-124 (2022)

\title{
POWERFUL ALGORITHM FOR ADAPTIVE RECOGNITION OF DYNAMIC SYSTEM PARAMETERS
}

\author{
Safwan Al Salaimeh ${ }^{1 *}$, Khaldoun Besoul ${ }^{2}$, Ayman Nayef Al Halaybeh ${ }^{2}$

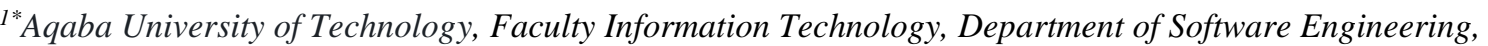 \\ Aqaba, Jordan; \\ ${ }^{2}$ King Khalid University, Faculty of Science and Arts, Computer Science Department, \\ Abha, Saudi Arabia; \\ "Corresponding Author Safwan Al Salaime, e-mail: safwan670@yahoo.com;
}

Received November 2021; Accepted December 2021; Published January 2022;

DOI: https://doi.org/10.31407/ijees12.114

\begin{abstract}
Objectives. The aim of this work is to propose an algorithm to solve the problem of adaptive identification of dynamic system parameters under uncertainty conditions with respect to drift parameters. Methods: Dynamic (temporal) characteristics are analyzed to form an image of adaptive systems in a turbulent atmosphere. The sterol parameter is calculated analytically based on the generalized Huygens-Kirchhoff principle. Results: The simulation result showed a fast approximation of the localized identification algorithms. Novelty: The proposed algorithm provides higher definition quality than the usual least squares weighted exponential method or competitive recognition algorithm.
\end{abstract}

Keywords: Adaptive system, Dynamic System, Algorithm, Limited Response Time, Modeling, Control. 